ARTICLE

\title{
Dual redox mediators accelerate the electrochemical kinetics of lithium-sulfur batteries
}

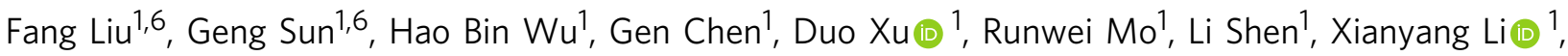

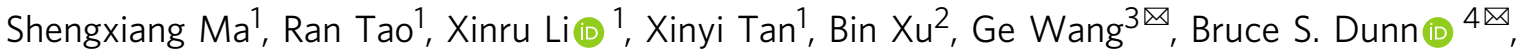 \\ Philippe Sautet (iD ${ }^{1,5 \times} \&$ Yunfeng Lu ${ }^{1 \times}$
}

The sluggish electrochemical kinetics of sulfur species has impeded the wide adoption of lithium-sulfur battery, which is one of the most promising candidates for next-generation energy storage system. Here, we present the electronic and geometric structures of all possible sulfur species and construct an electronic energy diagram to unveil their reaction pathways in batteries, as well as the molecular origin of their sluggish kinetics. By decoupling the contradictory requirements of accelerating charging and discharging processes, we select two pseudocapacitive oxides as electron-ion source and drain to enable the efficient transport of electron/ $\mathrm{Li}^{+}$to and from sulfur intermediates respectively. After incorporating dual oxides, the electrochemical kinetics of sulfur cathode is significantly accelerated. This strategy, which couples a fast-electrochemical reaction with a spontaneous chemical reaction to bypass a slow-electrochemical reaction pathway, offers a solution to accelerate an electrochemical reaction, providing new perspectives for the development of high-energy battery systems.

\footnotetext{
${ }^{1}$ Department of Chemical and Biomolecular Engineering, University of California, Los Angeles, CA, USA. ${ }^{2}$ State Key Laboratory of Supramolecular Structure and Materials, Jilin University, Changchun, China. ${ }^{3}$ Department of Materials Science and Engineering, University of Science and Technology Beijing, Beijing, China. ${ }^{4}$ Department of Materials Science and Engineering, University of California, Los Angeles, CA, USA. ${ }^{5}$ Department of Chemistry and Biochemistry, University of California, Los Angeles, CA, USA. ${ }^{6}$ These authors contributed equally: Fang Liu, Geng Sun. ${ }^{凶}$ email: gewang@mater.ustb.edu.cn; bdunn@ucla.edu; sautet@ucla.edu; luucla@ucla.edu
} 
T here is an increasing demand for high-energy batteries beyond lithium-ion batteries (LIBs) towards applications such as electric vehicles and drones ${ }^{1-3}$. Sulfur has been considered as one of the most promising candidates owing to its high theoretical energy density, environmental benignity, and low $\operatorname{cost}^{4,5}$. When paired with lithium ${ }^{6-8}$ or other anodes ${ }^{9-11}$, the energy density of the full cells can potentially surpass that of LIBs. However, the electrochemical reactions at sulfur cathodes involve multiple polysulfide intermediates with slow reaction kinetics, which results in batteries with low power and energy densities. In addition, outward diffusion of these soluble intermediate species within the cells results in the shuttling effect, deteriorating the capacity retention and shortening the cycling lifetime ${ }^{12}$. Extensive efforts have been made to address these issues, most of which were focused on confining the sulfur species within conductive scaffolds, such as porous carbon particles, graphene, and carbon nanotubes ${ }^{13,14}$. Meanwhile, physical and chemical barriers for the intermediate species were also explored to mitigate the shuttling effect ${ }^{15-17}$. Despite the extensive efforts, fabricating Li-S batteries with high-energy and high-power density remains highly challenging due to the difficulties in determining the critical active species and the reaction pathways at sulfur cathodes, limiting our ability to improve the electrode kinetics.

Based on first-principle calculations, here we construct the electronic energy diagram of various sulfur intermediates to enable a better understanding of the reaction pathways, and the molecular origin of their sluggish electrochemical reaction kinetics. Additionally, we propose a strategy to couple fast electrochemical reactions with spontaneous chemical reactions to circumvent the slow electrochemical reactions of sulfur species. By adding metal oxides as fast-responsive electron-ion reservoirs, which can rapidly react with the sulfur species during charging/ discharging process, sulfur cathodes with dramatically improved kinetics, energy, and power density are achieved.

\section{Results}

Electronic energy diagram of sulfur species. To provide the theoretical guidance toward the rational engineering of the electronic properties of electrode materials, we investigated the geometric and electronic structures of possible sulfur species using density functional theory (DFT) calculations with the B3LYP hybrid exchange-correlation functional (see Supplementary Note 1$)^{18-21}$. Considering that crystalline $\alpha$-sulfur is only weakly bonded through van der Waals interactions, isolated $\mathrm{S}_{8}$ molecule was used to study the electronic properties of sulfur species at the beginning of discharge. Our calculation suggests that cyclo- $\mathrm{S}_{8}$ exhibits a crown shape with a $D_{4 \mathrm{~h}}$ symmetry ${ }^{22}$ (Fig. 1a).

Additionally, lithium sulfide molecules $\left(\mathrm{Li}_{2} \mathrm{~S}_{\mathrm{n}}, 4 \leq n \leq 8\right)$ with different solvation structures were studied to illustrate their electronic structures. Each lithium cation can serve as a coordination center that complexes with solvent molecules (e.g., 1,3-dioxolane (DOL)) and sulfur chains. Although molecular dynamics (MD) simulation in general is the most appropriate method for the complex interactions between solvent and solvates, it is impractical to launch such time-consuming MD simulations with hybrid functionals. Here, we took an alternative approach and investigated the ensemble of solvated lithium sulfide species with different numbers of explicit solvent molecules, to reveal the general trend of their electronic properties. In the simulations, the first coordination shell of lithium cations is saturated explicitly by $0,1,2$, or 3 DOL molecules and/or sulfur atoms from the sulfur chains (formula is $\left.\mathrm{Li}_{2} \mathrm{~S}_{\mathrm{n}}-x \mathrm{DOL}: x=0,2,3,4,6\right)$. Additional environmental solvent molecules are taken into account by a polarizable continuum model ${ }^{23}$. We considered different lengths of sulfur chains $\left(\mathrm{Li}_{2} \mathrm{~S}_{\mathrm{n}}\right.$ : $n$ ranges from 4 to 8 ) to represent different states of charge (SOC). The representative structures are shown in Fig. 1a and Supplementary Table 1. In the case of high solvation level $(x=6)$, the $\mathrm{Li}_{2} \mathrm{~S}_{\mathrm{n}}$ species appear as chain structures, each lithium cations being coordinated with three oxygen atoms from three DOL molecules and a terminal sulfur atom. With fewer explicit solvation molecules $(x<6)$, the lithium cations may also bind with the middle sulfur atoms to fulfill their preferred high coordination number, forming a ring structure.

Radical intermediates also exist in the electrolytes, evidenced by the electron paramagnetic resonance (EPR) spectrum of a $\mathrm{Li}_{2} \mathrm{~S}_{6}$ solution that exhibits a typical $S=1 / 2 \mathrm{EPR}$ signal at $5 \mathrm{~K}$ (Supplementary Fig. 1) $)^{24,25}$. Four different radicals $\left(\mathrm{LiS}_{2}, \mathrm{LiS}_{3}\right.$, $\mathrm{LiS}_{4}$, and $\mathrm{LiS}_{5}$ ) in different solvation states were used to investigate their dimensionless magnetic moment ( $g$-factors) with DFT calculations (see Supplementary Note 2). It was found from the EPR spectrum that the magnetic moments of " $\mathrm{Li}_{2} \mathrm{~S}_{6}$ " solution are close to the $g$-factors of the $\mathrm{LiS}_{4}$ and $\mathrm{LiS}_{3}$ radicals regardless of their solvation states (Supplementary Table 2), indicating the presence these radicals in the solution and an exergonic dissociation (or disproportionation) from " $\mathrm{Li}_{2} \mathrm{~S}_{6}$ " to $\mathrm{LiS}_{4}$ and $\mathrm{LiS}_{3}$. Structural changes of solvated $\mathrm{LiS}_{\mathrm{m}}(m=2-5)$ radicals show a very similar trend as that in the $\mathrm{Li}_{2} \mathrm{~S}_{\mathrm{n}}$ series when the number of DOL molecules increases (Supplementary Table 3). $\mathrm{LiS}_{\mathrm{m}}$ form a ring structure with fewer DOL molecules $(x<3)$, and it turns into a chain structure with additional DOL molecules, where lithium cation forms a tetrahedral coordination with three oxygen atoms and one sulfur atom.

In addition, $\mathrm{Li}_{2} \mathrm{~S}_{2}$ is widely accepted as a primary product at the end of a discharge process or at the beginning of charge process $^{26}$. In this work, we adopted the structure determined by previous global optimization result (see Supplementary Note 3$)^{27}$. As shown in Fig. 1a, the unit cell of $\mathrm{Li}_{2} \mathrm{~S}_{2}$ is composed of a tetragonal cell with a $P 4_{2} / \mathrm{mnm}$ symmetry. This structure is formed by $\mathrm{LiS}_{4}$ tetrahedrons sharing edges and vertexes, in which sulfur atoms form $4 \mathrm{~S}-\mathrm{Li}$ ionic bonds and one S-S bond (2.117 ̊̊) with neighboring $\mathrm{LiS}_{4}$ tetrahedrons.

Furthermore, we investigated the electronic structures of these sulfur species based on their optimized structures. As shown in Fig. 1b, Cyclo- $\mathrm{S}_{8}$ shows a band gap of $4.59 \mathrm{eV}$, in accordance with its low electronic conductivity of $1 \times 10^{-15} \mathrm{~S} \mathrm{~cm}^{-1}$. Similarly, closed-shell $\mathrm{Li}_{2} \mathrm{~S}_{\mathrm{n}}-4 \mathrm{DOL}(n=4-8)$ exhibit large band gaps ranging from 2.91 to $3.76 \mathrm{eV}$, which increase gradually as sulfur chain gets shorter. This is consistent with the increasing overpotentials observed during discharge in the galvanostatic intermittent titration technique (GITT) tests ${ }^{28}$. In contrast, radical $\mathrm{LiS}_{\mathrm{m}}-2 \mathrm{DOL}$ species present significantly narrower band gaps $(1.72-2.07 \mathrm{eV})$, indicating these radical species are more electronically conductive comparing to $\mathrm{Li}_{2} \mathrm{~S}_{\mathrm{n}}$ species. Meanwhile, $\mathrm{Li}_{2} \mathrm{~S}_{2}$ presents a band gap of $2.29 \mathrm{eV}$ with the SCAN functional, which is a slightly larger value than that previously found with the PBE functional $(1.8 \mathrm{eV})^{27}$, but smaller than that with the hybrid functional HSE06 (3.04 eV, Supplementary Table 6). We will show later that our derived insights are not influenced by the small differences resulting from different functionals.

The electrochemical processes of a sulfur electrode are accompanied by redox reactions, during which electrons are extracted from (charging) or transferred to (discharging) these sulfur species. To illustrate this electrochemical process, we aligned their electronic band edges (i.e., lowest unoccupied molecular orbital (LUMO) and highest occupied molecular orbital (HOMO) for isolated molecules, or valence band maximum (VBM) and conduction band minimum (CBM) for solids) with respect to vacuum energy. As shown in Fig. 1b, sulfur species possess similar HOMO positions, suggesting they can be oxidized under a similar potential. Consistently, Li-S cells 
a
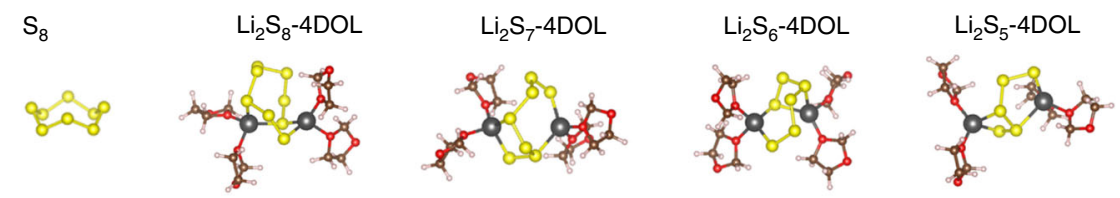

(vi) $\mathrm{Li}_{2} \mathrm{~S}_{4}-4 \mathrm{DOL}$
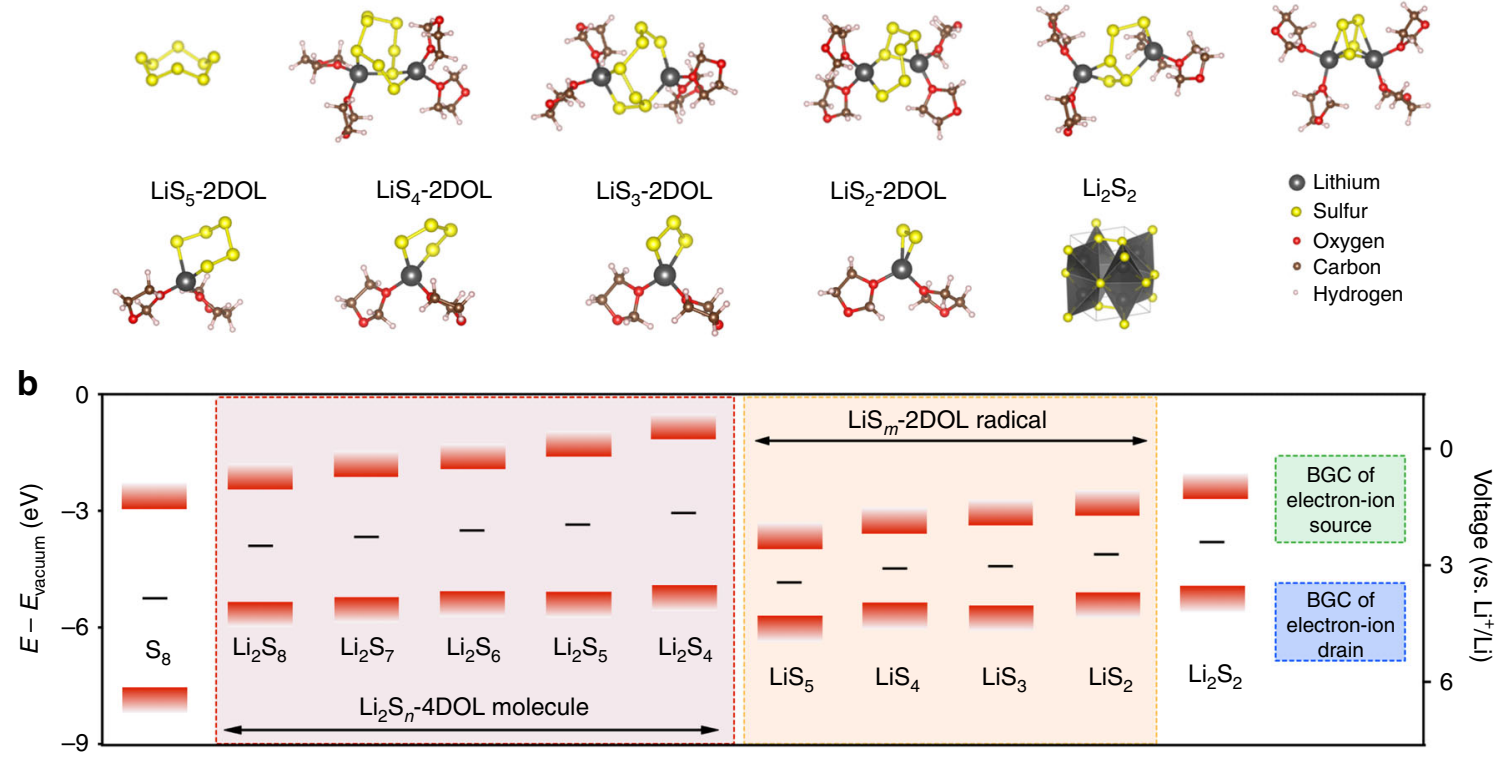

Fig. 1 Geometric and electronic structures of sulfur species. a The geometric structure of $\mathrm{S}_{8}, \mathrm{Li}_{2} \mathrm{~S}_{8}-4 \mathrm{DOL}, \mathrm{Li}_{2} \mathrm{~S}_{7}-4 \mathrm{DOL}, \mathrm{Li}_{2} \mathrm{~S}_{6}-4 D O \mathrm{~L}_{\text {, }} \mathrm{Li}_{2} \mathrm{~S}_{5}-4 D O L$, $\mathrm{Li}_{2} \mathrm{~S}_{4}-$ $4 \mathrm{DOL}, \mathrm{LiS}_{5}-2 \mathrm{DOL}$ radical, $\mathrm{LiS}_{4}-2 \mathrm{DOL}$ radical, $\mathrm{LiS}_{3}-2 \mathrm{DOL}$ radical, $\mathrm{LiS}_{2}-2 \mathrm{DOL}$ radical, and $\mathrm{Li}_{2} \mathrm{~S}_{2}$ solid. $\mathbf{b}$ Electronic band edges (highest occupied and lowest unoccupied levels, red bar) and band gap centers (black lines - ) of solvated sulfur species aligned with respect to vacuum energy (using hybrid functional B3LYP).

typically show a single anodic peak in their cyclic voltammetry profiles. Nevertheless, these sulfur species exhibit quite different LUMOs. Compared with $\mathrm{S}_{8}(\mathrm{LUMO}:-2.95 \mathrm{eV})$, the $\mathrm{Li}_{2} \mathrm{~S}_{\mathrm{n}}-4 \mathrm{DOL}$ species present significantly elevated LUMO positions that are increased with decreasing the length of sulfur-chain, indicating that shorter $\mathrm{Li}_{2} \mathrm{~S}_{\mathrm{n}}-4 \mathrm{DOL}$ species are more difficult to be reduced. On the contrary, the radicals, which are spontaneously formed in $\mathrm{Li}_{2} \mathrm{~S}_{\mathrm{n}}$ solutions, show much lower LUMO positions than those $\mathrm{Li}_{2} \mathrm{~S}_{\mathrm{n}}-4 \mathrm{DOL}$ regardless of the length of their sulfur chain. The comparison of these LUMO positions suggests that $\mathrm{LiS}_{\mathrm{m}}-2 \mathrm{DOL}$ radicals are easier to be reduced comparing to $\mathrm{Li}_{2} \mathrm{~S}_{\mathrm{n}}-4 \mathrm{DOL}$ species. Therefore, the continuous generation and consumption of $\mathrm{LiS}_{\mathrm{m}}$ radicals can provide a faster electrochemical pathway during discharge. In the meantime, considering the known deficiencies of DFT exchange correlation functionals, we also evaluated the band gap centers (BGCs) of sulfur species, which are marked as black lines in Fig. 1b. BGC, which are not sensitive to the choice of functional ${ }^{29}$ and formally correct from DFT calculations ${ }^{30}$, can precisely represent the redox potentials of different species. The BGCs shown in Fig. $1 \mathrm{~b}$ clearly suggest that $\mathrm{LiS}_{\mathrm{m}}-2 \mathrm{DOL}$ radicals present lower energies $(-4.12$ to $-4.18 \mathrm{eV})$ comparing to those of $\mathrm{Li}_{2} \mathrm{~S}_{\mathrm{n}}-4 \mathrm{DOL}(-3.9$ to $-3.05 \mathrm{eV})$, suggesting that these radical species can be electrochemically reduced before $\mathrm{Li}_{2} \mathrm{~S}_{\mathrm{n}}-4 \mathrm{DOL}$ species. This is consistent with the previous insights from our band gap calculations, that radicals play a critical role as the most active sulfur intermediates during the discharging process in lithium sulfur battery.

During an electrochemical reaction, electron transfer must occur between the reactant and the external circuit. The diffusion length for electrons that can tunnel through an insulating material (e.g., the sulfur species) is generally less than 1-2 $\mathrm{nm}^{31,32}$. This contradiction suggests that only the sulfur species, which are close enough to a conductive network (e.g., carbon black), can be electrochemically reacted. This argument implies that sulfur and sulfur intermediates are dissolved in the electrolyte, and these solvated species migrate to the neighboring conductive networks, where electron transfer and electrochemical reactions occur. Such a dissolution-diffusion-reaction mechanism is consistent with the observation of $\mathrm{Li}-\mathrm{S}$ cells, which generally require a high electrolyte to sulfur ratio (E/S) to achieve decent electrochemical performances ${ }^{33}$.

Pseudocapacitive oxides as electron-ion reservoirs. Towards sulfur cathodes with improved kinetics, it is essential to fabricate the electrodes with electron-ion transport networks to enable more efficient transport of electrons and $\mathrm{Li}^{+}$cations. In this circumstance, adapting conductive scaffolds with high specific surface areas may facilitate the electron transfer. However, increasing the surface area of the scaffolds generally reduces their pore volume and the corresponding mass loading of sulfur. An alternative strategy is to incorporate electron-ion reservoirs within the electrodes, which can dynamically and rapidly store and release electrons and $\mathrm{Li}^{+}$cations, while spontaneously react with the sulfur species along the electrochemical process. More specifically, such electron-ion reservoirs should be able to provide electrons and $\mathrm{Li}^{+}$cations to the sulfur species during discharging (serving as an electron-ion source during sulfur reduction). Meanwhile, such reservoirs should be able to accept electrons and $\mathrm{Li}^{+}$cations from the sulfur species during charging (serving as an electron-ion drain during sulfur oxidation).

We hypothesize that electron-ion reservoirs, which are similar to the biochemical mediators (such as $\mathrm{NADP}^{+} / \mathrm{NADPH}$ $\left(\mathrm{NADP}^{+}\right.$: nicotinamide adenine dinucleotide phosphate)), can be used to improve the reaction kinetics of sulfur cathodes. To fulfill the catalytic function, the BGC of electron-ion drain should be lower than the BGCs of sulfur radicals (i.e., $-4.84 \mathrm{eV}$ ) to accelerate the charging; while the BGC of electron-ion source should be higher than the BGCs of sulfur radicals (i.e., $-4.12 \mathrm{eV}$ ) to accelerate the discharging. Considering that the redox potential of the sulfur intermediates lies between $2.1-2.4 \mathrm{~V}$ (vs. $\mathrm{Li} / \mathrm{Li}^{+}$), the ideal redox potential for electron-ion reservoirs should be lower than $2.1 \mathrm{~V}$ and higher than $2.4 \mathrm{~V}$ (vs. $\mathrm{Li}^{2} \mathrm{Li}^{+}$), respectively. In addition, such electron-ion reservoirs should possess the 
a $\mathrm{Nb}_{2} \mathrm{O}_{5}$

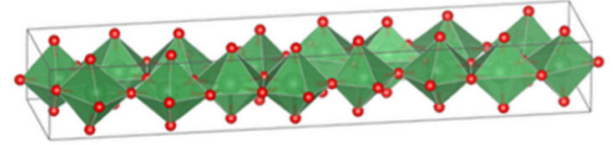

b

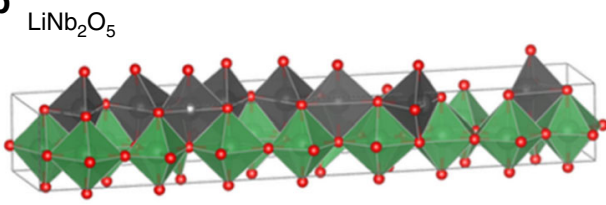

C $\mathrm{MnO}_{2}$

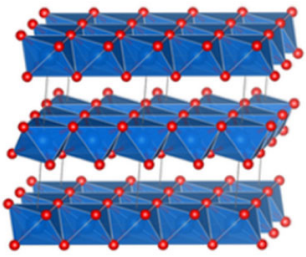

d $\quad \mathrm{Li}_{0.5} \mathrm{MnO}_{2}$

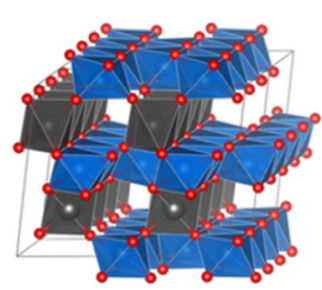

e

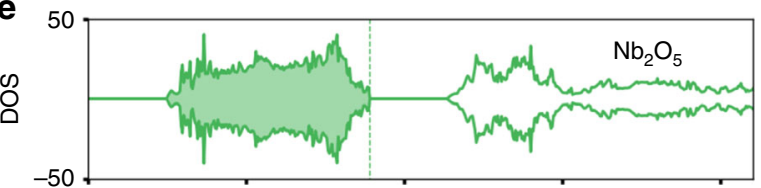

f
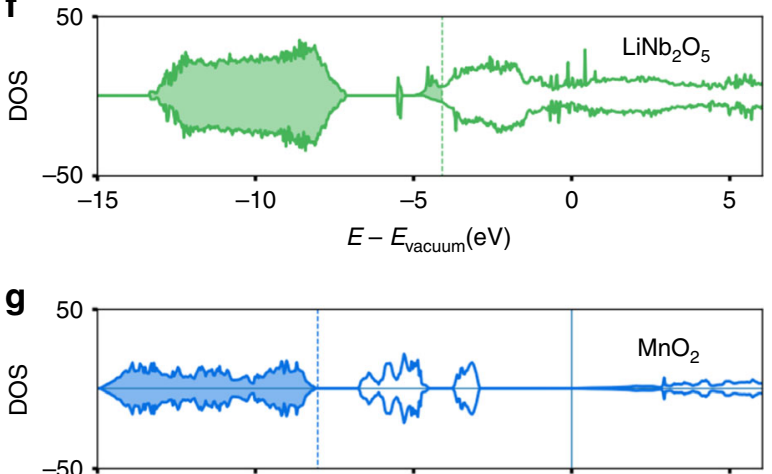

h

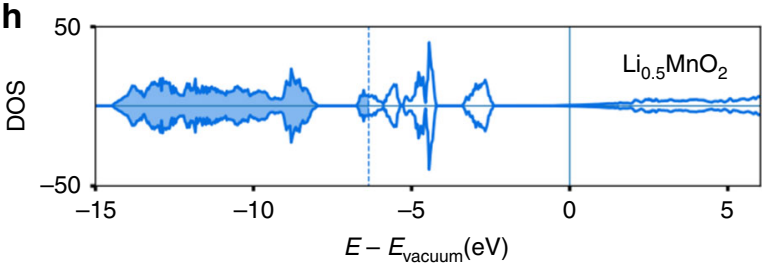

Fig. 2 Geometric and electronic structures of oxides. The geometric structure of a $\mathrm{Nb}_{2} \mathrm{O}_{5}, \mathbf{b} \mathrm{LiNb}_{2} \mathrm{O}_{5}, \mathbf{c} \mathrm{MnO}_{2}$, and $\mathbf{d} \mathrm{Li}_{0.5} \mathrm{MnO}_{2}$. The corresponding calculated electronic density of states of $\mathbf{e ~} \mathrm{Nb}_{2} \mathrm{O}_{5}, \mathbf{f} \mathrm{LiNb}_{2} \mathrm{O}_{5}, \mathbf{g} \mathrm{MnO}_{2}$, and $\mathbf{h} \mathrm{Li}_{0.5} \mathrm{MnO}_{2}$. Lithium, niobium, manganese, and oxygen atoms are shown in gray, green, blue, and red, respectively. Shadowed area represents filled valence band, while unfilled area indicates empty conduction band. The density of states are evaluated by SCAN functional.

capability to store and release electrons and $\mathrm{Li}^{+}$cations rapidly and dynamically. Based on these criteria, two pseudocapacitive oxides with fast electrochemical kinetics and long cycling lifetime, orthorhombic $\mathrm{Nb}_{2} \mathrm{O}_{5}$ and birnessite $\mathrm{MnO}_{2}$, were employed as representative electron-ion reservoirs in this work. Electrochemically, $\mathrm{Nb}_{2} \mathrm{O}_{5} / \mathrm{Li}_{x} \mathrm{Nb}_{2} \mathrm{O}_{5}(0<x<1.25)$ delivers the majority of its capacity between 1.2 and $2.0 \mathrm{~V}$ (vs. $\left.\mathrm{Li} / \mathrm{Li}^{+}\right)^{34,35}$, while $\mathrm{MnO}_{2}$ / $\mathrm{Li}_{\mathrm{y}} \mathrm{MnO}_{2}(0<y<1)$ is electrochemically active between 2.4 and $3.6 \mathrm{~V}$ (vs. $\left.\mathrm{Li} / \mathrm{Li}^{+}\right)^{36,37}$. Given that the redox potentials of $\mathrm{Nb}_{2} \mathrm{O}_{5}$ and $\mathrm{MnO}_{2}$ fall in the required ranges, they are employed as an electron-ion source and drain, respectively.

Using first-principle calculations, we investigated the geometric structures of $\mathrm{Nb}_{2} \mathrm{O}_{5}$ and $\mathrm{MnO}_{2}$ before and after lithiation (see Supplementary Note 4 and 5). As shown in Fig. 2a, orthorhombic $\mathrm{Nb}_{2} \mathrm{O}_{5}$ presents a unit cell with $\mathrm{NbO}_{6}$ octahedra and $\mathrm{NbO}_{7}$ pentagonal bipyramids connecting each other by sharing edges or vertexes $^{38,39}$ All the niobium cations are stacked layer by layer in the [001] direction forming a layered structure and the interlayer space is serving as fast $\mathrm{Li}^{+}$transport channel and storage space ${ }^{38}$. After lithiation, lithium cations occupy the interstices of $\mathrm{NbO}_{\mathrm{x}}$ polyhedrons (Fig. 2b), and the structure only experiences a slight expansion (Supplementary Table 4). The unit cell of birnessite $\mathrm{MnO}_{2}$ is in a hexagonal structure with $P_{63} / m m c$ symmetry (Fig. 2c) ${ }^{40,41}$. The $\mathrm{Mn}^{4+}$ cations are located in $\mathrm{MnO}_{6}$ octahedra that share edges within the same layer. The interlayer distance is rather large $(4.75 \AA)$, indicating a weak interaction between the layers. After lithiation, lithium cations selectively located in the interlayer region in a small $2 \times 2$ super cell. The Li cations stay at the center of the distorted octahedral site which is formed by three oxygen anions in the upper layer of $\mathrm{MnO}_{6}$ and three in the lower layer of $\mathrm{MnO}_{6}$ (Fig. 2d). $\mathrm{LiO}_{6}$ octahedra aligns in the [100] direction and no face-sharing structure are formed between $\mathrm{LiO}_{6}$ octahedron and $\mathrm{MnO}_{6}$ octahedron (Supplementary Table 5).

Figure $2 \mathrm{e}-\mathrm{h}$ illustrate the density of states (DOS) for the oxides. $\mathrm{Nb}_{2} \mathrm{O}_{5}$ (Fig. 2e) and $\mathrm{MnO}_{2}$ (Fig. $2 \mathrm{~g}$ ) present moderate band gaps. Calculated values can be functional dependent, with $2.36 \mathrm{eV}$ (resp. $2.55 \mathrm{eV}$ ) for $\mathrm{Nb}_{2} \mathrm{O}_{5}$ and $1.2 \mathrm{eV}$ (resp. $2.95 \mathrm{eV}$ ) for $\mathrm{MnO}_{2}$ with the SCAN (resp. the HSE06) functional. BGC values are however much less sensitive to the functional choice, with differences smaller than $0.2 \mathrm{eV}$. The DOS shows that, more importantly, the lithiation process barely changes the shape of their valence bands, but significantly lowers their absolute band energies or elevates fermi energies (Fig. $2 \mathrm{f}, \mathrm{h}$ ). This is related with the electrostatic interaction between lithium $2 s$ and oxygen $2 p$ orbitals that also enables fast ionic transport within the structure. Given that their conduction bands are partially filled after lithium insertion, $\mathrm{LiNb}_{2} \mathrm{O}_{5}$ and $\mathrm{Li}_{0.5} \mathrm{MnO}_{2}$ are expected to exhibit high electronic conductivity due to their metallic characteristics. The minimum structural distortion during lithiation and delithiation, as well as the high electronic conductivities of $\mathrm{Nb}_{2} \mathrm{O}_{5}$ and $\mathrm{MnO}_{2}$ also facilitate fast electrochemical response.

Electron-ion reservoirs mediated electrochemical reactions. Figure $3 \mathrm{a}$ shows the electronic band edges and BGCs of the sulfur species and the oxides with respect to vacuum energy. During the discharging of sulfur electrodes (reduction of the sulfur intermediates), electrons and $\mathrm{Li}^{+}$are inserted into $\mathrm{Nb}_{2} \mathrm{O}_{5}$ converting it to $\mathrm{LiNb}_{2} \mathrm{O}_{5}$, generating an electron-ion source. Subsequently, asstored electrons and $\mathrm{Li}^{+}$in the $\mathrm{LiNb}_{2} \mathrm{O}_{5}$ can be transferred to sulfur species (e.g., $\mathrm{LiS}_{\mathrm{m}}$ radicals) spontaneously, facilitating their reduction reactions. Meanwhile, $\mathrm{LiNb}_{2} \mathrm{O}_{5}$ is converted back to 


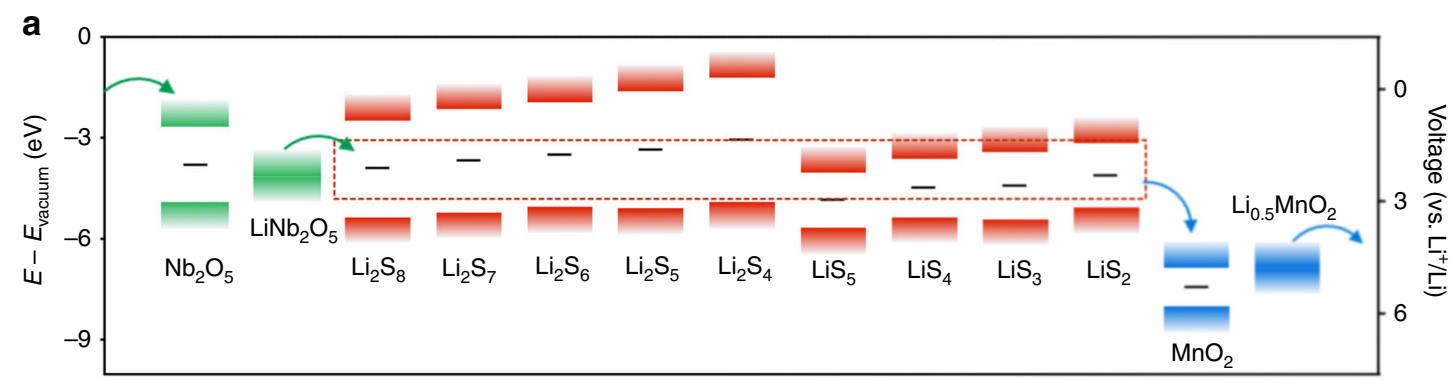

b
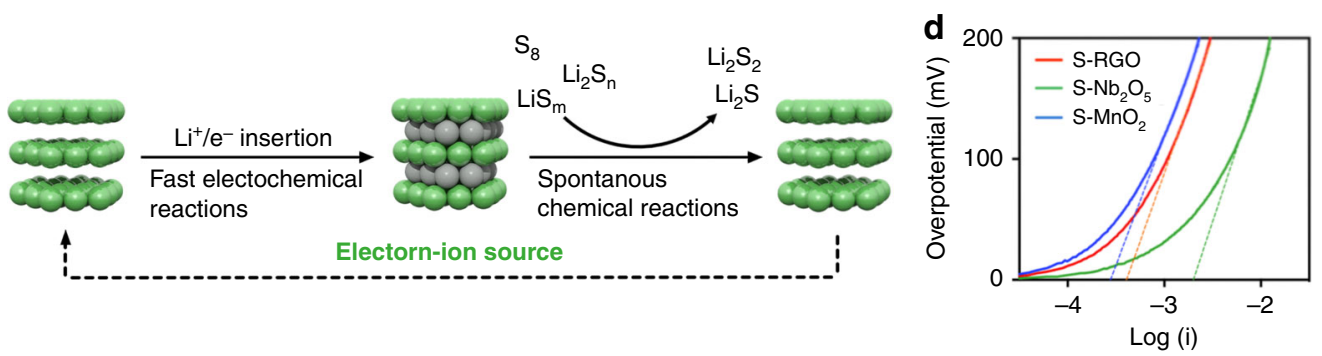

C
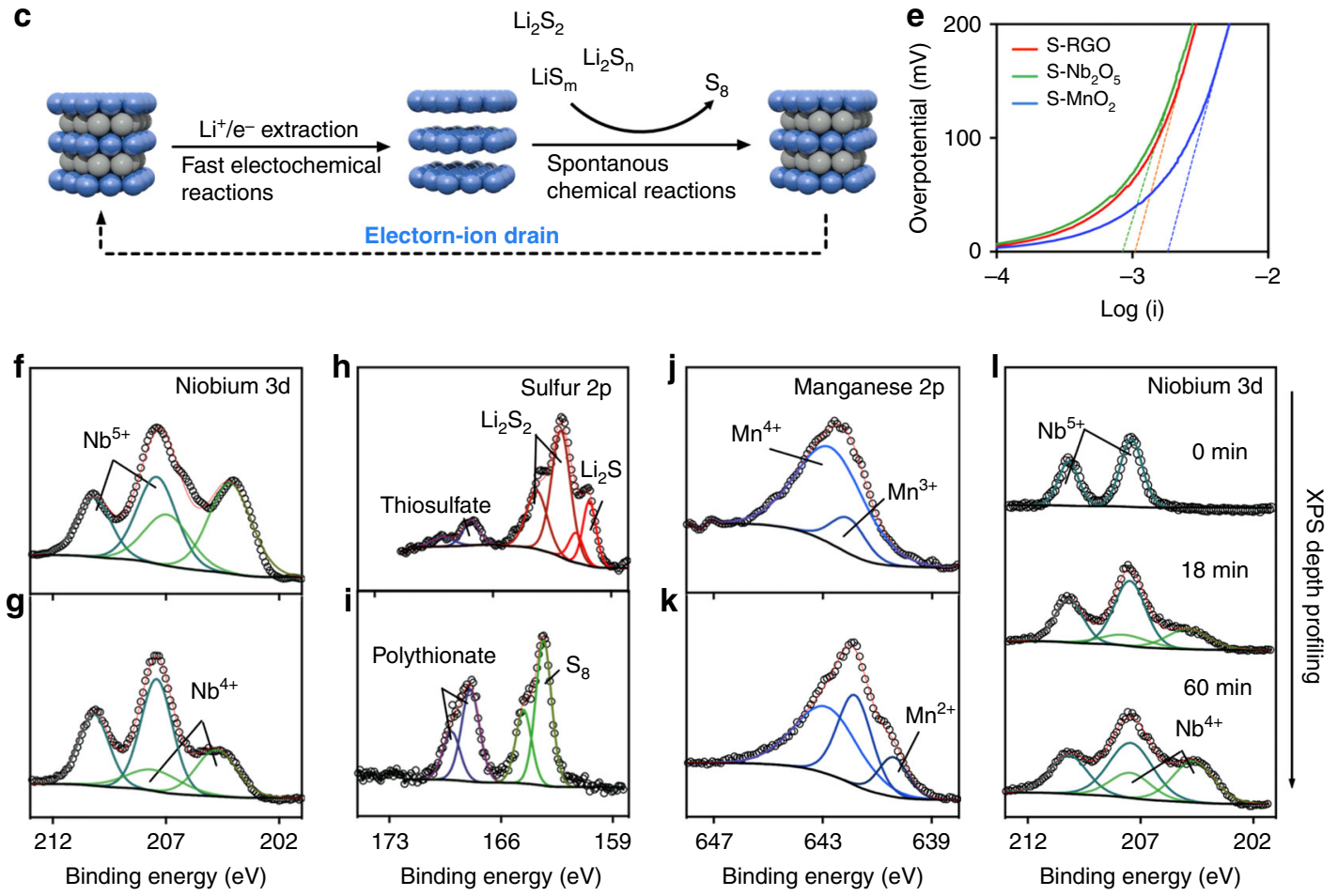

Fig. 3 Electron transfers between oxides and sulfur species. a Electron transfer pathways at the sulfur cathode with the presence of electron-ion reservoirs. $\mathrm{Li}_{2} \mathrm{~S}_{\mathrm{n}}$ molecules and $\mathrm{LiS}_{\mathrm{m}}$ radicals are in solvated states. Schematic illustration of electrochemical and chemical reaction coupling strategy to enhance electrochemical kinetics during $\mathbf{b}$ discharging and $\mathbf{c}$ charging process. Tafel plot of $\mathrm{RGO}, \mathrm{Nb}_{2} \mathrm{O}_{5}, \mathrm{MnO}_{2}$ composites in 50 mM Li $\mathrm{S}_{6}$ catholyte during $\mathbf{d}$ cathodic scan and $\mathbf{e}$ anodic scan. Niobium $3 d$ spectrum of $\mathbf{f} \mathrm{LiNb}_{2} \mathrm{O}_{5}$ and $\mathbf{g} \mathrm{LiNb}_{2} \mathrm{O}_{5}-\mathrm{Li}_{2} \mathrm{~S}_{6}$ composites. Sulfur $2 p$ spectrum of $\mathbf{h} \mathrm{LiNb}_{2} \mathrm{O}_{5}-\mathrm{Li}_{2} \mathrm{~S}_{6}$ composites and $\mathbf{i} \mathrm{MnO}_{2}-\mathrm{Li}_{2} \mathrm{~S}_{6}$ composites. Manganese $2 p$ spectrum of $\mathbf{j} \mathrm{MnO}_{2}$ and $\mathbf{k} \mathrm{MnO}_{2}-\mathrm{Li}_{2} \mathrm{~S}_{6}$ composites. I XPS depth profiling of $\mathrm{Nb}_{2} \mathrm{O}_{5}$ electrode in $50 \mathrm{mM} \mathrm{Li} 2 \mathrm{~S}_{6}$ catholyte at $2.4 \mathrm{~V}$ vs. $\left(\mathrm{Li} / \mathrm{Li}^{+}\right)$during discharging.

$\mathrm{Nb}_{2} \mathrm{O}_{5}$, which can be regenerated after accepting electrons and $\mathrm{Li}^{+}$from the external circuit and electrolyte, respectively. Given that $\mathrm{Li}_{2} \mathrm{~S}_{\mathrm{n}}$ molecules can be spontaneously converted into $\mathrm{LiS}_{\mathrm{m}}$ radicals (Supplementary Fig. 1) with lower BGCs (stronger oxidizing agents), the continuous reaction between $\mathrm{LiS}_{\mathrm{m}}$ radicals and $\mathrm{Nb}_{2} \mathrm{O}_{5} / \mathrm{LiNb}_{2} \mathrm{O}_{5}$ prompts the conversion from $\mathrm{Li}_{2} \mathrm{~S}_{\mathrm{n}}$ to $\mathrm{Li}_{2} \mathrm{~S}_{2} / \mathrm{Li}_{2} \mathrm{~S}$. This process can also be explained from an atomic-scale perspective. As the driving force of electrochemical process, electron transfer process is always accompanied by subsequent transport of $\mathrm{Li}^{+}$to the same location/species. For example, during discharging, the reduced sulfide species $\left(\mathrm{Li}_{2} \mathrm{~S}_{\mathrm{n}} / \mathrm{LiS}_{\mathrm{m}}\right.$ with an extra electron) have to complex with $\mathrm{Li}^{+}$in a fast manner to minimize the drop of cell potential. As a supercapacitor material, $\mathrm{Nb}_{2} \mathrm{O}_{5} /$ $\mathrm{LiNb}_{2} \mathrm{O}_{5}$ can store significantly more electron/ $\mathrm{Li}^{+}\left(160 \mathrm{mAh} \mathrm{g}{ }^{-1}\right.$ under a current density of $20 \mathrm{~mA} \mathrm{~g}^{-1}$, corresponding to $0.1 \mathrm{C}$ rate $)^{42}$ compared to that of carbon $\left(5 \mathrm{mAh} \mathrm{g}^{-1}\right.$ under a current density of $\left.20 \mathrm{~mA} \mathrm{~g}^{-1}\right)^{43}$, and in particular fast $\mathrm{Li}^{+}$transport can be realized without significant change in electrochemical potential. Therefore, $\mathrm{Nb}_{2} \mathrm{O}_{5} / \mathrm{LiNb}_{2} \mathrm{O}_{5}$ species can stabilize the reduced sulfur species locally and timely, resulting in an efficient 
discharging interface. In contrast, carbon particles are less efficient in stabilizing the reduced sulfide species and require large overpotential to drive this electrochemical process. In the meantime, sulfur intermediates bind stronger with $\mathrm{Nb}_{2} \mathrm{O}_{5}$ / $\mathrm{LiNb}_{2} \mathrm{O}_{5}$ as evidenced on Fig. $3 \mathrm{~h}$, which also prompts the electron transfer process.

Similarly, during the charging process (oxidation of the sulfur intermediates), electrons and $\mathrm{Li}^{+}$are extracted from $\mathrm{Li}_{0.5} \mathrm{MnO}_{2}$, forming an electron-ion drain $\mathrm{MnO}_{2}$. As shown in Fig. 3a, the BGC of $\mathrm{MnO}_{2}$ is lower than those of the sulfur intermediates, allowing the flow of the electrons from $\mathrm{Li}_{2} \mathrm{~S}_{\mathrm{n}} / \mathrm{LiS}$ m to $\mathrm{MnO}_{2}$. The continuous regeneration of $\mathrm{MnO}_{2}$ from $\mathrm{Li}_{0.5} \mathrm{MnO}_{2}$, and the spontaneous reaction between sulfur species and $\mathrm{MnO}_{2}$ drive the conversion from $\mathrm{Li}_{2} \mathrm{~S}_{\mathrm{n}} / \mathrm{LiS}_{\mathrm{m}}$ to $\mathrm{S}_{8}$. From the atomic-scale perspective, the presence of $\mathrm{Li}_{0.5} \mathrm{MnO}_{2} / \mathrm{MnO}_{2}$ enables the efficient migration of $\mathrm{Li}^{+}$away from the oxidized sulfide species $\left(\mathrm{Li}_{2} \mathrm{~S}_{\mathrm{n}} /\right.$ $\mathrm{LiS}_{\mathrm{m}}$ with an electron hole), ensuring the continuity of the charging process even under high current densities.

Linear voltammetry was employed to evaluate the conversion rate of sulfur intermediates in the presence of different oxides. We synthesized orthorhombic $\mathrm{Nb}_{2} \mathrm{O}_{5}$ and birnessite $\mathrm{MnO}_{2}$ nanoparticles on reduced graphene oxide (RGO) using a hydrothermal method. As shown in Supplementary Fig. 2, these crystalline nanoparticles are homogenously grown on the RGO sheets with a weight percentage around $10 \mathrm{wt} \%$ (Supplementary Fig. 3). These carbon/oxide composites were mixed with polymeric binders and carbon black to form electrodes, which were subjected to linear voltammetry with $\mathrm{Li}_{2} \mathrm{~S}_{6}$ catholyte. Figure $3 \mathrm{~d}$, e present the Tafel plots of the electrodes of $\mathrm{RGO}, \mathrm{Nb}_{2} \mathrm{O}_{5} / \mathrm{RGO}$, and $\mathrm{MnO}_{2} / \mathrm{RGO}$. These plots deviate sharply from a linear behavior as the overpotential $(\eta)$ approaches to zero, while the linear segments are extrapolated to an interception of $\log i_{0}$. According to the Butler-Volmer model, the standard rate constant $\left(k^{0}\right)$ of an electrochemical reaction is proportional to its exchange current $\left(i_{0}\right)$. As shown in Fig. $3 \mathrm{~d}$, the $\mathrm{Nb}_{2} \mathrm{O}_{5} / \mathrm{RGO}$ electrode exhibits a much higher $i_{0}$ in comparison with that of the RGO electrode (2 vs. $0.41 \mathrm{~mA}$ ). During anodic scans, the $i_{0}$ of the $\mathrm{RGO}, \mathrm{Nb}_{2} \mathrm{O}_{5} /$ RGO or $\mathrm{MnO}_{2} / \mathrm{RGO}$ electrodes is $1.0 \mathrm{~mA}, 0.85 \mathrm{~mA}$, and $1.82 \mathrm{~mA}$, respectively, suggesting that the oxidative kinetics for the $\mathrm{MnO}_{2}$ / RGO electrode is $82 \%$ faster than that of the RGO electrode (Fig. 3e). Collectively, these studies confirm $\mathrm{Nb}_{2} \mathrm{O}_{5} / \mathrm{LiNb}_{2} \mathrm{O}_{5}$ and $\mathrm{MnO}_{2} / \mathrm{Li}_{0.5} \mathrm{MnO}_{2}$ can be used as effective electron-ion reservoirs/ drains for sulfur cathodes.

On the other hand, CV scanning tests can reveal the difference in the apparent diffusion coefficient of lithium ions $D\left(\mathrm{Li}^{+}\right)$in the electrodes. Here, we used these carbon/oxide composites as the carbon hosts and synthesized sulfur composites with a sulfur loading of $80 \mathrm{wt} \%$ (Supplementary Fig. 4), and further fabricated electrodes using slurry casting method (Supplementary Fig. 5). Given that the weight percentages of oxide nanoparticles in the carbon/sulfur composite are around $2 \mathrm{wt} \%$, such a small amount does not significanltly change the charge transfer resistence or the ionic conductivity of the cathodes (Supplementary Fig. 6). We investigated the electrochemical responses of sulfur cathodes under different sweep rates ranging from 0.1 to $0.5 \mathrm{mV} \mathrm{s}^{-1}$ (Supplementary Fig. 7). These cathodes exhibit two cathodic peaks, which can be attributed to the reduction of $S_{8}$ to sulfur intermediates $\left(i_{\mathrm{p}}^{\mathrm{c}, 1}\right)$ and their subsequent reduction to $\mathrm{Li}_{2} \mathrm{~S}_{2} / \mathrm{Li}_{2} \mathrm{~S}$ $\left(i_{\mathrm{p}}^{\mathrm{c}, 2}\right)$. During the anodic sweep, there is one peak resulting from the conversion of $\mathrm{Li}_{2} \mathrm{~S}_{2} / \mathrm{Li}_{2} \mathrm{~S}$ to sulfur intermediates and $\mathrm{S}_{8}\left(i_{\mathrm{p}}^{\mathrm{a}}\right)$. All three cathodes exhibit a linear relationship between cathodic/ anodic peak currents $\left(I_{\mathrm{p}}\right)$ and the square root of sweep rates $(v)$, indicating a diffusion-limited process (Supplementary Fig. 7b-d). According to classical Randles-Sevcik equation, the slope of the curve $\left(I_{\mathrm{p}} / v^{0.5}\right)$ correlates to the diffusion coefficient of lithium ions $D\left(\mathrm{Li}^{+}\right)$of the corresponding electrochemical step. Supplementary Fig. 7e compares the relative $D\left(\mathrm{Li}^{+}\right)$of three sulfur composites normalized by that of S-RGO. During the cathodic sweep, both $\mathrm{Nb}_{2} \mathrm{O}_{5}$ and $\mathrm{MnO}_{2}$ promote the conversion from $\mathrm{S}_{8}$ to $\mathrm{Li}_{2} \mathrm{~S}_{\mathrm{n}}$, whereas only $\mathrm{Nb}_{2} \mathrm{O}_{5}$ assists the formation of $\mathrm{Li}_{2} \mathrm{~S}_{2} / \mathrm{Li}_{2} \mathrm{~S}$. On the other hand, the mediation effect of $\mathrm{MnO}_{2}$ is more pronounced on charge, facilitating the oxidation of sulfur species to $S_{8}$. The conclusion from the CV scanning test is consistent with that from the Tafel plot.

Experimentally, the electron transfer between $\mathrm{LiNb}_{2} \mathrm{O}_{5}, \mathrm{MnO}_{2}$ and the sulfur species was demonstrated using $\mathrm{Li}_{2} \mathrm{~S}_{6}$ solution as a representative. Upon mixing with $\mathrm{LiNb}_{2} \mathrm{O}_{5}$, the color of the $\mathrm{Li}_{2} \mathrm{~S}_{6}$ solution changed from brown to yellow (Supplementary Fig. 8). The solid product was then separated from the solution and analyzed with XPS. As shown in Fig. $3 \mathrm{f}$, g, the content of $\mathrm{Nb}^{4+}$ (core level shift (CLS) 203.4, 206.1 eV) 44,45 in $\mathrm{LiNb}_{2} \mathrm{O}_{5}$ is decreased from 48.8 to $30 \%$ after the reaction, indicating that $\mathrm{LiNb}_{2} \mathrm{O}_{5}$ was oxidized. Correspondingly, the sulfur $2 p$ spectrum illustrates the reduction of $\mathrm{Li}_{2} \mathrm{~S}_{6}$ with the formation of $\mathrm{Li}_{2} \mathrm{~S}_{2}$ (CLS $161.7 \mathrm{eV}$ ) and $\mathrm{Li}_{2} \mathrm{~S}$ (CLS $\left.160 \mathrm{eV}\right)^{46,47}$ (Fig. 3h). Besides, a small amount of thiosulfate group $\left(\left[\mathrm{S}_{2} \mathrm{O}_{3}\right]^{2-} \text {, CLS } 166.8 \mathrm{eV}\right)^{17,47}$ is formed on the surface, which could serve as the active site for electron transfers. A similar electron transfer process was also observed between $\mathrm{Li}_{2} \mathrm{~S}_{6}$ and $\mathrm{MnO}_{2}$, which is mainly composed of $\mathrm{Mn}^{4+}$ (CLS $\left.643 \mathrm{eV}\right)^{48}$ (Fig. 3j). Upon the addition of $\mathrm{MnO}_{2}$, the $\mathrm{Li}_{2} \mathrm{~S}_{6}$ solution changes to colorless (Supplementary Fig. 8). XPS studies suggest that $\mathrm{Mn}^{4+}$ is reduced to $\mathrm{Mn}^{3+}(\mathrm{CLS} 642 \mathrm{eV})$ and $\mathrm{Mn}^{2+}\left(\mathrm{CLS} 640.2 \mathrm{eV}\right.$ ) (Fig. 3k), while $\mathrm{Li}_{2} \mathrm{~S}_{6}$ is oxidized to $\mathrm{S}_{8}$ (CLS $163.3 \mathrm{eV})^{46,47}$ (Fig. 3i). Meanwhile, polythionate group (CLS $167.9 \mathrm{eV})$, which is composed of thiosulfate groups and sulfur chain, is also generated on the surface of $\mathrm{MnO}_{2}$. These experiments imply that, when the band edges of the metal oxides are properly aligned with the band structures of active sulfur species (radicals in this case), chemical reactions can occur spontaneously between the metal oxide and the sulfur species. Such chemical reactions circumvent the slow electrochemical pathway between the sulfur species and carbon electrode, leading to improved sulfur reaction kinetics.

Thermodynamically, the redox reaction of $\mathrm{Nb}_{2} \mathrm{O}_{5}$ mainly occurs between 1.2 and $2.0 \mathrm{~V}$ vs. $\mathrm{Li} / \mathrm{Li}^{+}$; one may be concerned that $\mathrm{LiNb}_{2} \mathrm{O}_{5}$ can be not generated at the discharge voltage of sulfur cathodes (2.1-2.4 V vs. $\left.\mathrm{Li} / \mathrm{Li}^{+}\right)$. In terms of electrochemical kinetics, $\mathrm{Nb}_{2} \mathrm{O}_{5}$ is a pseudocapacitive oxide with extremely fast kinetics (e.g., $\sim 70 \%$ of capacity retention with increasing the current density from 0.2 to $20 \mathrm{~A} \mathrm{~g}^{-1}$ ), especially when compared with sluggish battery materials. During the discharging process, particularly under a high current density, it is possible that $\mathrm{Nb}_{2} \mathrm{O}_{5}$ within sulfur cathodes is preferably lithiated, forming $\mathrm{LiNb}_{2} \mathrm{O}_{5}$ with a transiting local voltage lower than $2.0 \mathrm{~V}$. Subsequent reaction of the $\mathrm{LiNb}_{2} \mathrm{O}_{5}$ with the sulfur species, followed by regeneration of $\mathrm{LiNb}_{2} \mathrm{O}_{5}$, constructs a mediated electrochemical reaction with accelerated electrochemical kinetics.

This effect was confirmed by ex situ XPS analysis, where $0.5 \mathrm{M}$ LiTFSI and $50 \mathrm{mM} \mathrm{Li}_{2} \mathrm{~S}_{6}$ solution was used as the catholyte, and $\mathrm{Nb}_{2} \mathrm{O}_{5}$ electrode and lithium foil were employed as the working and counter electrode, respectively. The cell was scanned at a constant sweep rate of $5 \mathrm{mV} \mathrm{s}^{-1}$, during which the sweeping was stopped at $2.4 \mathrm{~V}$ vs. $\mathrm{Li}_{/} \mathrm{Li}^{+}$and the electrode was subject to an XPS analysis. Figure $3 \mathrm{l}$ show the XPS spectra of the $\mathrm{Nb}_{2} \mathrm{O}_{5}$ electrode before and after etching for $18 \mathrm{~min}$, and $60 \mathrm{~min}$ using an Argon-ion gun, respectively. As expected, increasing amount of $\mathrm{Nb}^{4+}$ was found towards the current collector from the liquidelectrode interface. This observation confirms that $\mathrm{Nb}_{2} \mathrm{O}_{5}$ can be effectively converted to $\mathrm{LiNb}_{2} \mathrm{O}_{5}$ even at an electrode voltage 

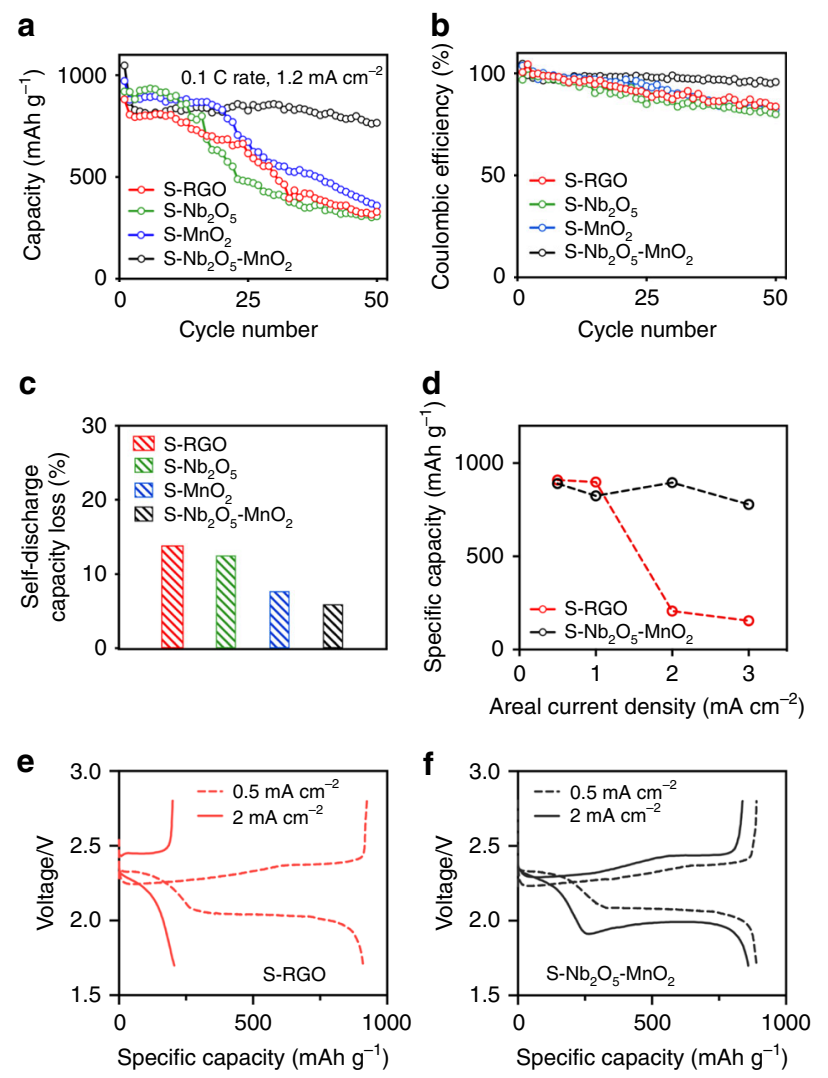

Fig. 4 Electrochemical performance of lithium-sulfur batteries with/

without oxides. a, $\mathbf{b}$ Galvanostatic cycling performance of sulfur electrodes under a current density of $167.5 \mathrm{~mA} \mathrm{~g}^{-1}$ ( $0.1 \mathrm{C}$ rate). c Self-discharge capacity loss of sulfur electrodes after resting for $24 \mathrm{~h}$ at $2.1 \mathrm{~V}\left(\mathrm{vs} . \mathrm{Li}^{+} / \mathrm{Li}\right)$ during the $5^{\text {th }}$ cycle. d Specific capacities of S-RGO and $\mathrm{S}-\mathrm{Nb}_{2} \mathrm{O}_{5}-\mathrm{MnO}_{2}$ electrodes under various current densities. e Representative voltage-capacity profiles of S-RGO electrode and $\mathbf{f} \mathrm{S}-\mathrm{Nb}_{2} \mathrm{O}_{5}-\mathrm{MnO}_{2}$ electrode under current densities of 0.5 and $2.0 \mathrm{~mA} \mathrm{~cm}^{-2}$.

higher than $2.0 \mathrm{~V}$. The increasing content of $\mathrm{Nb}^{4+}$ towards the current collector is consistent with the reaction of the sulfur species with $\mathrm{LiNb}_{2} \mathrm{O}_{5}$, as well as diffusion of the sulfur species to the interior of the electrode.

Electrochemical performance of sulfur cathodes with electronion reservoirs. The energy density of lithium-sulfur battery is closely related to the mass loading of sulfur in cathode and the ratio between electrolyte to sulfur $(E / S)$. Although $\mathrm{Nb}_{2} \mathrm{O}_{5}$ and $\mathrm{MnO}_{2}$ have been incorporated into sulfur cathodes before, they have not been evaluated side-by-side in thick sulfur electrodes with precisely control amount of electrolyte. The electrochemical behaviors obtained from previous thin electrodes can't be readily transformed into that of thick electrodes in practical applications. Herein, we used thick sulfur cathodes (areal mass loading of $7 \mathrm{mg}$ $\mathrm{cm}^{-2}$ ) with an $E / S$ ratio of 7 in coin cell as a proof-of-concept demonstration. The fast conversion of sulfur intermediates is expected to suppress the outward dissolution of polysulfides and enhance capacity retention.

Figure 4a shows the specific capacity of the sulfur electrodes with different oxides under a current density of $1.67 \mathrm{~mA} \mathrm{~g}^{-1}$, corresponding to $0.1 \mathrm{C}$ rate. After 50 cycles, the $\mathrm{S}-\mathrm{Nb}_{2} \mathrm{O}_{5}-\mathrm{MnO}_{2}$ electrode still delivers a reversible capacity of $767.2 \mathrm{mAh} \mathrm{g}^{-1}$, whereas the S-RGO electrode experiences a fast capacity decay after ten cycles and maintains a low capacity of $329.9 \mathrm{mAh} \mathrm{g}^{-1}$ at the $50^{\text {th }}$ cycles. Consistently with the significant improvement in cycling stability, the $\mathrm{S}-\mathrm{Nb}_{2} \mathrm{O}_{5}-\mathrm{MnO}_{2}$ electrode shows significantly improved Coulombic efficiency (Fig. 4b). For comparison, we also evaluated the cycling stability of sulfur electrodes with $\mathrm{Nb}_{2} \mathrm{O}_{5}$ or $\mathrm{MnO}_{2}$ under the same testing conditions. Although $\mathrm{S}-\mathrm{Nb}_{2} \mathrm{O}_{5}$ and $\mathrm{S}-\mathrm{MnO}_{2}$ electrodes present slightly enhanced specific capacities comparing to that of S-RGO electrode during the initial ten cycles, they only maintained marginal improvements after 50 cycles (S-RGO: $329.9 \mathrm{mAh} \mathrm{g}^{-1}, \mathrm{~S}-\mathrm{Nb}_{2} \mathrm{O}_{5}$ : $307.6 \mathrm{mAh} \mathrm{g} \mathrm{g}^{-1}, \mathrm{~S}-\mathrm{MnO}_{2}$ : $359.8 \mathrm{mAh} \mathrm{g}^{-1}$ ). The capacity decay observed in $\mathrm{S}-\mathrm{Nb}_{2} \mathrm{O}_{5}$ (or $\mathrm{S}-\mathrm{MnO}_{2}$ ) electrodes can be attributed to the inefficient utilization of sulfur species, during the subsequent charging (or discharging) process. The slow conversion of sulfur intermediates leads to their accumulation in the electrolyte, prompts their side-reactions with lithium metal anode, and results in the drop of Coulombic efficiency. This comparison further demonstrated the importance of having both $\mathrm{Nb}_{2} \mathrm{O}_{5} / \mathrm{LiNb}_{2} \mathrm{O}_{5}$ and $\mathrm{Li}_{0.5} \mathrm{MnO}_{2} / \mathrm{MnO}_{2}$ as electronion reservoirs in thick sulfur electrodes to accelerate both discharging and charging processes. In addition, we want to point it out that incorporating oxides in thin sulfur electrodes where the transport of electrons $/ \mathrm{Li}^{+}$is sufficiently fast, the improvement in electrochemical performance can be marginal or even negligible (Supplementary Fig. 9).

Meanwhile, the efficient conversion of sulfur intermediates also minimizes the outward diffusion of sulfur species, and mitigates resulted self-discharging capacity loss (Fig. 4c). Newly assembled $\mathrm{Li}-\mathrm{S}$ cells were cycled at $0.05 \mathrm{C}$ rate $\left(1 \mathrm{C}=1675 \mathrm{~mA} \mathrm{~g}^{-1}\right)$ for the first cycle and then at $0.1 \mathrm{C}$ rate for three cycles. During the $5^{\text {th }}$ cycle, the discharging process was paused at $2.1 \mathrm{~V}$ (vs. $\mathrm{Li}^{+} / \mathrm{Li}$ ) where the generation of soluble lithium polysulfides is maximum. After resting for $24 \mathrm{~h}$, the discharging process is resumed. Here, we define the self-discharge capacity loss as $\left(C_{4}-C_{5}\right) / C_{4} \times 100 \%$ where $C_{n}$ represent the discharge capacity during the $n^{\text {th }}$ cycle. The capacity loss observed in $\mathrm{S}-\mathrm{Nb}_{2} \mathrm{O}_{5}-\mathrm{MnO}_{2}$ electrode is the lowest among all four electrodes (S-RGO: $13.88 \%, \mathrm{~S}-\mathrm{Nb}_{2} \mathrm{O}_{5}$ : $\left.12.53 \%, \mathrm{~S}-\mathrm{MnO}_{2}: 7.7 \%, \mathrm{~S}-\mathrm{Nb}_{2} \mathrm{O}_{5}-\mathrm{MnO}_{2}: 5.93 \%\right)$, re-illustrating the necessity of having both oxides in the cathode. In addition, no obvious polysulfide shuttling or decrease in CE (Supplementary Fig. 10) were observed during the subsequent charging process in all four Li-S cells. Different from the irreversible capacity loss observed in thin electrodes, the majority of the capacity loss in thick electrodes can be recovered in the next cycle (Supplementary Fig. 11), which may be attributed to limited amount of electrolyte and the associated high viscosity.

To explore the potential applications of $\mathrm{S}-\mathrm{Nb}_{2} \mathrm{O}_{5}-\mathrm{MnO}_{2}$ electrodes under high power demands, we evaluated their electrochemical behaviors under various current densities ranging from 0.5 to $3 \mathrm{~mA} \mathrm{~cm}^{-2}$ (Fig. $4 \mathrm{~d}$ ). To avoid the influence from the fast degradation of lithium metal anodes under such harsh conditions, we choose to run the galvanostatic test under each current density for only one cycle instead of multiple cycles. $\mathrm{S}-\mathrm{Nb}_{2} \mathrm{O}_{5}-\mathrm{MnO}_{2}$ electrode exhibits excellent electrochemical behaviors by delivering comparable specific capacities under such large range of current densities. S-RGO electrode, which delivers a similar specific capacity under a small current density of $0.5 \mathrm{~mA} \mathrm{~cm}^{-2}$, presents completely different electrochemical response under high current densities. When the current density is increased to $2 \mathrm{~mA} \mathrm{~cm}^{-2}$, the capacity from the second discharging plateau of sulfur cannot be utilized, resulting in a pronounced drop of available capacity (206.4 $\mathrm{mAh} \mathrm{g}^{-1}$ ) in S-RGO electrode (Fig. 4e). This result is consistent with the sluggish transport of electrons from carbon matrix and $\mathrm{Li}^{+}$from the limited electrolyte in sulfur electrodes. In contrast, with the assistance of $\mathrm{Nb}_{2} \mathrm{O}_{5} / \mathrm{Li}_{\mathrm{x}} \mathrm{Nb}_{2} \mathrm{O}_{5}$ (electron-ion source) and $\mathrm{MnO}_{2}$ / $\mathrm{Li}_{\mathrm{y}} \mathrm{MnO}_{2}$ (electron-ion drain), the transport electrons $/ \mathrm{Li}^{+}$to and from sulfur species can be dramatically accelerated, leading to 
efficient utilization of active materials even under fast discharging and charging conditions (Fig. 4f). These studies collectively confirm a dramatically improved electrochemical kinetics upon the addition of the dual oxides in thick sulfur cathodes.

In addition, the advantage of using dual redox mediators becomes more pronounced with lower content of electrolyte (Supplementary Fig. 12a, b). When $E / S$ ratio is 7 , the initial capacity of S-RGO and $\mathrm{S}-\mathrm{Nb}_{2} \mathrm{O}_{5}-\mathrm{MnO}_{2}$ electrodes at $0.05 \mathrm{C}$ rate are similar. However, when the $E / S$ ratio is lowered to 5 , the utilization of sulfur in S-RGO significantly decreased with a large voltage drop of the second plateau. In contrast, the electrochemical behavior of $\mathrm{S}-\mathrm{Nb}_{2} \mathrm{O}_{5}-\mathrm{MnO}_{2}$ electrode remains similar disregard of the decreased amount of electrolyte, delivering a much higher energy density on the cell level (Supplementary Fig. 12c). Of note, a number of materials (e.g., oxides ${ }^{49}$, sulfides $^{50,51}$, nitrides ${ }^{52}$, and carbides $^{53}$ ) have been explored to enhance the redox kinetics of sulfur electrodes as well. Given that the pseudocapacitive $\mathrm{Nb}_{2} \mathrm{O}_{5}-\mathrm{MnO}_{2}$ dual redox mediators enabled the fast and efficient transport of electron $/ \mathrm{Li}^{+}$both to and from sulfur intermediates, it leads to $\mathrm{Li}-\mathrm{S}$ cells with better rate performance (Supplementary Fig. 13).

\section{Discussion}

In this work, we investigate the electronic structures of all possible sulfur species involved in lithium-sulfur batteries and construct an electronic energy diagram to illustrate their reaction pathways. By decoupling the contradictory requirements for the acceleration of charging and discharging processes, we rationally select two pseudocapacitive oxides $\left(\mathrm{Nb}_{2} \mathrm{O}_{5} / \mathrm{Li}_{\mathrm{x}} \mathrm{Nb}_{2} \mathrm{O}_{5}\right.$ and $\left.\mathrm{MnO}_{2} / \mathrm{Li}_{\mathrm{y}} \mathrm{MnO}_{2}\right)$ as electron-ion reservoirs (source and drain), which can enable the efficient transport of electron/ $\mathrm{Li}^{+}$to and from sulfur intermediates respectively. Adapting such electron-ion reservoirs enables the fabrication of sulfur electrodes with fast electrochemical kinetics, leading to enhanced areal capacity and power performance, as well as prolonged cycling life. This strategy that couples a fast electrochemical reaction with a spontaneous chemical reaction to circumvent an sluggish electrochemical reaction can be readily extended to other electrode materials with slow electrochemical kinetics such as silicon and phosphorus, opening a new avenue for lithium batteries and other electrochemical devices.

\section{Methods}

Synthesis of RGO and RGO-metal oxides composites. Reduced graphene oxide (RGO) was prepared by oxidation of natural graphite flacks (Sigma-Aldrich) following the Hummers method followed by reduction using ascorbic acid (SigmaAldrich) at $90^{\circ} \mathrm{C}$ for $2 \mathrm{~h}(\mathrm{pH}=10)$. The resulted solid product was washed with deionized water for several times until $\mathrm{pH}$ reaches 7 . After freeze-drying, $\mathrm{RGO}$ was obtained.

The $\mathrm{RGO}-\mathrm{Nb}_{2} \mathrm{O}_{5}$ composites were synthesized according to the previously reported procedure. Briefly, $25 \mathrm{mg} \mathrm{NbCl}_{5}$ (Sigma-Aldrich) was dissolved in $5 \mathrm{~mL}$ of ethanol (Fisher Scientific). In a separate vial, $110.7 \mathrm{mg} \mathrm{RGO}$ was dispersed in $50 \mathrm{~mL}$ ethanol by sonication. Both vials were chilled in ice bath for $2 \mathrm{~h}$. The two solutions were then mixed while $0.5 \mathrm{~mL}$ oleylamine (Sigma-Aldrich) and $8.3 \mu \mathrm{L}$ deionized water were slowly injected. The solution was heated at $75^{\circ} \mathrm{C}$ in an oil bath with magnetic stirring for $6 \mathrm{~h}$. The resulted product was washed with ethanol and water to remove excess oleylamine and then freeze-dried. After annealing at $600{ }^{\circ} \mathrm{C}$ for $3 \mathrm{~h}$ in argon, $\mathrm{RGO}-\mathrm{Nb}_{2} \mathrm{O}_{5}$ composites were obtained.

The RGO- $\mathrm{MnO}_{2}$ composites were synthesized at room temperature. First, $3.175 \mathrm{mg} \mathrm{MnSO}_{4} \cdot \mathrm{H}_{2} \mathrm{O}$ (Sigma-Aldrich) was dissolved in $2.5 \mathrm{~mL}$ deionized water. In a separate vial, $109.5 \mathrm{mg}$ RGO was dispersed in $15 \mathrm{~mL}$ deionized water by sonication. The two solutions were then mixed and form a homogenous solution. Then, $10 \mathrm{mg} \mathrm{KMnO}$ (Sigma-Aldrich) was dissolved in $2.5 \mathrm{~mL}$ deionized water and added to the previous solution. This solution was further stirred at room temperature for $12 \mathrm{~h}$. The resulting solid product was washed with water for several times and then freeze dried.

Synthesis of S-RGO and S-RGO-metal oxide composites. The sulfur and RGO composites (denoted as S-RGO composites) were prepared using a liquid infiltration method at $159^{\circ} \mathrm{C}$ for $4 \mathrm{~h}$. S- $-\mathrm{Nb}_{2} \mathrm{O}_{5}$ composites, $\mathrm{S}-\mathrm{MnO}_{2}$ composites and $\mathrm{S}-\mathrm{Nb}_{2} \mathrm{O}_{5}-\mathrm{MnO}_{2}$ were synthesized via similar method by replacing RGO with RGO- $\mathrm{Nb}_{2} \mathrm{O}_{5}, \mathrm{RGO}-\mathrm{MnO}_{2}$, and mixed RGO- $\mathrm{Nb}_{2} \mathrm{O}_{5}$ and $\mathrm{RGO}-\mathrm{MnO}_{2}$ composites (weight ratio =1:1). The weight ratio between sulfur and RGO (or RGO-metal oxides composites) was 4:1.

Preparation of sulfur cathodes. Sulfur cathodes were prepared using a slurry casting method. Carbon/sulfur composites, carbon fiber (Pyrograf Product Inc.) and sodium alginate (Sigma-Aldrich, $4 \mathrm{wt} \%$ solution in deionized water) were mixed with a weight ratio of 8:1:1 to form a homogenous slurry, which was casted onto carbon-coated aluminum foil with a doctor blade. The resulting electrodes were dried at $70^{\circ} \mathrm{C}$ in vacuum for $4 \mathrm{~h}$.

Preparation of $\mathbf{L i}_{2} \mathbf{S}_{6}$ solution. Twenty millimolar of $\mathrm{Li}_{2} \mathrm{~S}_{6}$ solution was prepared by mixing stoichiometric amounts of elemental sulfur (Sigma-Aldrich) and $\mathrm{Li}_{2} \mathrm{~S}$ (Alfa Aesar) in DOL: DME (Sigma-Aldrich, volume ratio 1:1). A homogenous dark-yellow solution of $\mathrm{Li}_{2} \mathrm{~S}_{6}$ was obtained after stirring for $24 \mathrm{~h}$ at $130{ }^{\circ} \mathrm{C}$.

Electrochemical measurements. To evaluate the electrochemical performance, 2032-type coin cells (MTI Corporation) were assembled with polypropylene separator (Celgard 2500), and lithium foil (Alfa Aesar) as the anodes. 0.5 M LiTFSI (Sigma-Aldrich) and $2 \mathrm{wt} \% \mathrm{LiNO}_{3}$ (Sigma-Aldrich) in DOL/DME was used as electrolyte. Cyclic voltammetry analysis was performed on a Bio-Logic VMP3 electrochemical workstation with a three-electrode configuration. Lithium foils were used as both counter electrode and reference electrode. Linear voltammetry analysis was performed on Solartron 1860/1287 electrochemical interface with twoelectrode configuration. $0.5 \mathrm{M}$ LiTFSI and $0.1 \mathrm{M} \mathrm{Li}_{2} \mathrm{~S}_{6}$ in DOL/DME solution was used as the catholyte and lithium foil was used as the counter electrode. Galvanostatic charge-discharge measurements were carried out using Land CT2000 battery tester in a voltage range of $1.7-2.8 \mathrm{~V}$ for all rates. Specific capacities were calculated with respect to the mass of sulfur.

Material characterization. XRD measurements were performed on Rigaku MiniFlex instrument using the copper Ka radiation $(\lambda=1.54 \AA)$. TGA was performed on a TA Instrument SDT Q600 employing a heating rate of $5^{\circ} \mathrm{C} \mathrm{min}{ }^{-1}$ from 40 to $700^{\circ} \mathrm{C}$ under airflow. SEM and TEM studies were conducted on a ZEISS Supra 40VP and Titan S/TEM, respectively. For XPS studies, the samples were sealed in a transporter in the Argon-filled glove box before being quickly transferred to the high-vacuum chamber of XPS (AXIS Ultra DLD) for analysis. All the spectra were fitted to Gaussian-Lorentzian functions and a Shirley-type background using CasaXPS software. The binding energy values were all calibrated using $\mathrm{C} 1 \mathrm{~s}$ peak at $284.5 \mathrm{eV}$.

DFT calculations. The periodic structures including $\mathrm{MnO}_{2}, \mathrm{Li}_{0.5} \mathrm{MnO}_{2}, \mathrm{Nb}_{2} \mathrm{O}_{5}$ $\mathrm{LiNb}_{2} \mathrm{O}_{5}$, and $\mathrm{Li}_{2} \mathrm{~S}_{2}$ are calculated with VASP ${ }^{54-58}$. The SCAN functional ${ }^{59}$ is used for describing the exchange-correlation interactions for solid systems. It has been shown that SCAN functional is very accurate for the electronic structure of $\mathrm{MnO}_{2}$, alkali intercalated $\mathrm{MnO}_{2}$, and a wide range of materials $\mathrm{s}^{60-62}$. The energy cutoff for plane waves is $400 \mathrm{eV}$. The density of k-mesh is large enough to make sure that the energy difference is smaller than $0.01 \mathrm{eV} /$ unit cell. HOMO/LUMO positions of isolated molecules including $\mathrm{S}_{8}, \mathrm{LiS}_{4}$, and $\mathrm{LiS}_{3}$ radicals are calculated with the Gaussian09 package $^{63}$ at the level of B3LYP functional level with $6-311++(d, p)$ basis sets.

Alignment of absolute band positions. We used the following scheme to align the band edge positions (including VBM and CBM) of different materials with the vacuum energy:

$$
E_{\mathrm{i}}=\left[E_{\mathrm{i}}^{\text {bulk }}-E_{\text {ref }}^{\text {bulk }}\right]+\left[E_{\text {ref }}^{\text {slab }}-E_{\text {vac }}^{\text {slab }}\right] .
$$

The first term calculates the difference between band edge energy $E_{\mathrm{i}}$ (which is either VBM or CBM) and a reference state $E_{\text {ref. }}$. Here we use the energy of a semicore orbital as the reference state. The second term calculates the difference between the reference state and vacuum energy in the slab model. The reference state is chosen as the semicore orbitals because they are rarely influenced by their chemical environment. In this work, we choose the $4 s$ orbital of niobium atom, $3 s$ orbital of manganese atom, $1 \mathrm{~s}$ of lithium atom (for $\mathrm{Li}_{2} \mathrm{~S}_{2}$ only) as the reference state, respectively. It should be notated that the energy of semicore orbitals can be also influenced by the Madelung potential. If the adopting slab model is too thin, the Madelung potential will be different between bulk and thin slab. Therefore, we ensured the slab model has a sufficient large thickness (larger than $35 \AA$ ) in all the calculations to minimize the difference of the Madelung potential at the center of the slab.

\section{Data availability}

The data that support the plots within this article and other findings in this study are available from the corresponding author upon reasonable request. 
Received: 20 April 2020; Accepted: 13 August 2020;

Published online: 15 October 2020

\section{References}

1. Tarascon, J. M. \& Armand, M. Issues and challenges facing rechargeable lithium batteries. Nature 414, 359-367 (2001).

2. Goodenough, J. B. \& Park, K.-S. The Li-ion rechargeable battery: a perspective. J. Am. Chem. Soc. 135, 1167-1176 (2013).

3. Li, M., Lu, J., Chen, Z. \& Amine, K. 30 Years of lithium-ion batteries. Adv. Mater. 30, 1800561 (2018).

4. Ji, X. \& Nazar, L. F. Advances in Li-S batteries. J. Mater. Chem. 20, 9821 (2010).

5. Bruce, P. G., Freunberger, S. A., Hardwick, L. J. \& Tarascon, J.-M. Li- $\mathrm{O}_{2}$ and Li-S batteries with high energy storage. Nat. Mater. 11, 19-29 (2011).

6. Liu, J. et al. Pathways for practical high-energy long-cycling lithium metal batteries. Nat. Energy 4, 180-186 (2019).

7. Lin, D., Liu, Y. \& Cui, Y. Reviving the lithium metal anode for high-energy batteries. Nat. Nanotechnol. 12, 194-206 (2017).

8. Fang, C., Wang, X. \& Meng, Y. S. Key issues hindering a practical lithiummetal anode. Trends Chem. 1, 152-158 (2019).

9. Lu, J., Chen, Z., Pan, F., Cui, Y. \& Amine, K. High-performance anode materials for rechargeable lithium-ion batteries. Electrochem. Energy Rev. 1, 35-53 (2018).

10. Chan, C. K. et al. High-performance lithium battery anodes using silicon nanowires. Nat. Nanotechnol. 3, 31-35 (2008).

11. Li, M. et al. Design strategies for nonaqueous multivalent-ion and monovalent-ion battery anodes. Nat. Rev. Mater. 5, 276-294 (2020).

12. Mikhaylik, Y. V. \& Akridge, J. R. Polysulfide shuttle study in the Li/S battery system. J. Electrochem. Soc. 151, A1969 (2004).

13. Yang, Y., Zheng, G. \& Cui, Y. Nanostructured sulfur cathodes. Chem. Soc. Rev. 42, 3018-3032 (2013).

14. Manthiram, A., Fu, Y., Chung, S.-H., Zu, C. \& Su, Y.-S. Rechargeable lithiumsulfur batteries. Chem. Rev. 114, 11751-11787 (2014)

15. Yan, N. et al. Fabrication of a nano-Li-channel interlayer for high performance Li-S battery application. RSC Adv. 5, 26273-26280 (2015).

16. Su, Y.-S. \& Manthiram, A. A new approach to improve cycle performance of rechargeable lithium-sulfur batteries by inserting a free-standing MWCNT interlayer. Chem. Commun. 48, 8817-8819 (2012).

17. Liu, F. et al. Regenerative polysulfide-scavenging layers enabling lithium-sulfur batteries with high energy density and prolonged cycling life. ACS Nano 11, 2697-2705 (2017).

18. Stephens, P. J., Devlin, F. J., Chabalowski, C. F. \& Frisch, M. J. Ab initio calculation of vibrational absorption and circular dichroism spectra using density functional force fields. J. Phys. Chem. 98, 11623-11627 (1994).

19. Becke, A. D. Density-functional thermochemistry. III. The role of exact exchange. J. Chem. Phys. 98, 5648 (1993).

20. Becke, A. D. Density-functional exchange-energy approximation with correct asymptotic behavior. Phys. Rev. A 38, 3098-3100 (1988).

21. Lee, C., Yang, W. \& Parr, R. G. Development of the Colle-Salvetti correlationenergy formula into a functional of the electron density. Phys. Rev. B Condens. Matter 37, 785-789 (1988).

22. Meyer, B. Elemental sulfur. Chem. Rev. 76, 367-388 (1976)

23. Tomasi, J., Mennucci, B. \& Cammi, R. Quantum mechanical continuum solvation models. Chem. Rev. 105, 2999-3093 (2005).

24. Vijayakumar, M. et al. Molecular structure and stability of dissolved lithium polysulfide species. Phys. Chem. Chem. Phys. 16, 10923-10932 (2014).

25. Wang, Q. et al. Direct observation of sulfur radicals as reaction media in lithium sulfur batteries. J. Electrochem. Soc. 162, A474-A478 (2015).

26. Paolella, A. et al. Transient existence of crystalline lithium disulfide $\mathrm{Li}_{2} \mathrm{~S}_{2}$ in a lithium-sulfur battery. J. Power Sources 325, 641-645 (2016).

27. Yang, G., Shi, S., Yang, J. \& Ma, Y. Insight into the role of $\mathrm{Li}_{2} \mathrm{~S}_{2}$ in $\mathrm{Li}-\mathrm{S}$ batteries: a first-principles study. J. Mater. Chem. A 3, 8865-8869 (2015).

28. Zhang, Y. et al. High sulfur loading lithium-sulfur batteries based on a upper current collector electrode with lithium-ion conductive polymers. J. Mater. Chem. A 5, 97-101 (2017).

29. Toroker, M. C. et al. First principles scheme to evaluate band edge positions in potential transition metal oxide photocatalysts and photoelectrodes. Phys. Chem. Chem. Phys. 13, 16644-16654 (2011).

30. Perdew, J. P. \& Levy, M. Physical content of the exact Kohn-Sham orbital energies: band gaps and derivative discontinuities. Phys. Rev. Lett. 51, 1884-1887 (1983).

31. Rosen, J. Encyclopedia of Physics. (Infobase Publishing, New York, 2009).

32. Kittel, C. Introduction to Solid State Physics, 7th edn. (Wiley India Pvt. Limited, Hoboken, 2007).
33. Lu, D. et al. Enabling high-energy-density cathode for lithium-sulfur batteries ACS Appl. Mater. Interfaces 10, 23094-23102 (2018).

34. Augustyn, V. et al. High-rate electrochemical energy storage through $\mathrm{Li}+$ intercalation pseudocapacitance. Nat. Mater. 12, 518-522 (2013).

35. Sun, H. et al. Three-dimensional holey-graphene/niobia composite architectures for ultrahigh-rate energy storage. Science 356, 599-604 (2017).

36. Tan, H., Wang, S. \& Lei, X. New insights for the cyclic performance of Li/ $\mathrm{MnO}_{2}$ batteries using a simple electrochemical process. J. Electrochem. Soc. 162, A448-A452 (2015)

37. Wang, D. et al. $\beta-\mathrm{MnO}_{2}$ as a cathode material for lithium ion batteries from first principles calculations. Phys. Chem. Chem. Phys. 15, 9075-9083 (2013).

38. Chen, D. et al. Unraveling the nature of anomalously fast energy storage in T$\mathrm{Nb}_{2} \mathrm{O}_{5}$. J. Am. Chem. Soc. 139, 7071-7081 (2017).

39. Pinto, M. B., Soares, A. L., Mella Orellana, A., Duarte, H. A. \& De Abreu, H. A. Structural, electronic, and thermodynamic properties of the $\mathrm{T}$ and $\mathrm{B}$ phases of niobia: first-principle calculations. J. Phys. Chem. A 121, 2399-2409 (2017).

40. Kitchaev, D. A., Dacek, S. T., Sun, W. \& Ceder, G. Thermodynamics of phase selection in $\mathrm{MnO}_{2}$ framework structures through alkali intercalation and hydration. J. Am. Chem. Soc. 139, 2672-2681 (2017).

41. Gaillot, A.-C. et al. Structure of synthetic K-rich Birnessite obtained by hightemperature decomposition of $\mathrm{KMnO}_{4}$. I. Two-layer polytype from $800{ }^{\circ} \mathrm{C}$ experiment. Chem. Mater. 15, 4666-4678 (2003).

42. Griffith, K. J., Forse, A. C., Griffin, J. M. \& Grey, C. P. High-rate intercalation without nanostructuring in metastable $\mathrm{Nb}_{2} \mathrm{O}_{5}$ bronze phases. J. Am. Chem. Soc. 138, 8888-8899 (2016).

43. Nilssen, B. E. Stability of conductive carbon additives for high-voltage Li-ion battery cathodes. (Norwegian University of Science and Technology, 2014).

44. Zhou, P. et al. Effect of concurrent joule heat and charge trapping on RESET for NbAlO fabricated by atomic layer deposition. Nanoscale Res. Lett. 8, 91 (2013).

45. Rahman, M. M. et al. A vein-like nanoporous network of $\mathrm{Nb}_{2} \mathrm{O}_{5}$ with a higher lithium intercalation discharge cut-off voltage. J. Mater. Chem. A 1, 11019 (2013).

46. Diao, Y., Xie, K., Xiong, S. \& Hong, X. Insights into Li-S battery cathode capacity fading mechanisms: irreversible oxidation of active mass during cycling. J. Electrochem. Soc. 159, A1816-A1821 (2012)

47. Liang, X. et al. A highly efficient polysulfide mediator for lithium-sulfur batteries. Nat. Commun. 6, 5682 (2015).

48. Nesbitt, H. W. \& Banerjee, D. Interpretation of XPS Mn(2p) spectra of Mn oxyhydroxides and constraints on the mechanism of $\mathrm{MnO}_{2}$ precipitation. $\mathrm{Am}$. Mineral. 83, 305-315 (1998).

49. Mei, $\mathrm{S}$. et al. Porous $\mathrm{Ti}_{4} \mathrm{O}_{7}$ particles with interconnected-pore structure as a high-efficiency polysulfide mediator for lithium-sulfur batteries. Adv. Funct. Mater. 27, 1701176 (2017).

50. Xue, W. et al. Intercalation-conversion hybrid cathodes enabling Li-S full-cell architectures with jointly superior gravimetric and volumetric energy densities. Nat. Energy 4, 374-382 (2019).

51. Shin, W., Lu, J. \& Ji, X. ZnS coating of cathode facilitates lean-electrolyte Li-S batteries. Carbon Energy 1, 165-172 (2019).

52. Deng, D.-R. et al. $\mathrm{Co}_{4} \mathrm{~N}$ nanosheet assembled mesoporous sphere as a matrix for ultrahigh sulfur content lithium-sulfur batteries. ACS Nano 11, 6031-6039 (2017).

53. Bao, W., Su, D., Zhang, W., Guo, X. \& Wang, G. 3D metal carbide@mesoporous carbon hybrid architecture as a new polysulfide reservoir for lithium-sulfur batteries. Adv. Funct. Mater. 26, 8746-8756 (2016).

54. Kresse, G. \& Joubert, D. From ultrasoft pseudopotentials to the projector augmented-wave method. Phys. Rev. B 59, 1758-1775 (1999).

55. Kresse, G. \& Furthmüller, J. Efficient iterative schemes for ab initio totalenergy calculations using a plane-wave basis set. Phys. Rev. B 54, 11169-11186 (1996).

56. Kresse, G. \& Furthmüller, J. Efficiency of ab-initio total energy calculations for metals and semiconductors using a plane-wave basis set. Comp. Mater. Sci. 6 , 15-50 (1996).

57. Kresse, G. \& Hafner, J. Ab initio molecular-dynamics simulation of the liquidmetal-amorphous-semiconductor transition in germanium. Phys. Rev. B Condens. Matter 49, 14251-14269 (1994).

58. Kresse, G. \& Hafner, J. Ab initio molecular dynamics for liquid metals. Phys. Rev. B 47, 558-561 (1993).

59. Sun, J., Ruzsinszky, A. \& Perdew, J. P. Strongly constrained and appropriately normed semilocal density functional. Phys. Rev. Lett. 115, 036402 (2015).

60. Zhang, Y. et al. Efficient first-principles prediction of solid stability: Towards chemical accuracy. npj Comput. Mater. 4, 9 (2018).

61. Kitchaev, D. A. et al. Energetics of polymorphs in density functional theory. Phys. Rev. B 93, 045132 (2016).

62. Park, H., Koh, H. S. \& Siegel, D. J. First-principles study of redox end members in lithium-sulfur batteries. J. Phys. Chem. C 119, 4675-4683 (2015).

63. Frisch, M. J. et al. Gaussian 09 (Gaussian, Inc., Wallinggord CT, 2009). 


\section{Acknowledgements}

The authors acknowledge the use of instruments at the Electron Imaging Center for NanoMachines supported by CNSI at UCLA.

\section{Author contributions}

F.L., G.S., G.W., B.S.D., P.S., and Y.L. conceived the concept. G.S. and P.S. designed the DFT models. F.L. synthesized the materials, conducted the electrochemical tests and analyzed the results. G.S. performed the DFT calculations. H.B.W., G.C., R.M., and L.S. conducted the TEM and SEM analysis. X.L., S.M., R.T., and X.T. performed TGA and XPS analysis. D.X., H.B.W., X.L. and B.X. helped with data analysis. F.L. and G.S contributed equally to this work. All authors discussed the results and commented on the manuscript.

\section{Competing interests}

The authors declare no competing interests.

\section{Additional information}

Supplementary information is available for this paper at https://doi.org/10.1038/s41467020-19070-8

Correspondence and requests for materials should be addressed to G.W., B.S.D., P.S. or Y.L.
Peer review information Nature Communications thanks the anonymous reviewers for their contribution to the peer review of this work.

Reprints and permission information is available at http://www.nature.com/reprints

Publisher's note Springer Nature remains neutral with regard to jurisdictional claims in published maps and institutional affiliations.

(c) (i) Open Access This article is licensed under a Creative Commons Attribution 4.0 International License, which permits use, sharing, adaptation, distribution and reproduction in any medium or format, as long as you give appropriate credit to the original author(s) and the source, provide a link to the Creative Commons license, and indicate if changes were made. The images or other third party material in this article are included in the article's Creative Commons license, unless indicated otherwise in a credit line to the material. If material is not included in the article's Creative Commons license and your intended use is not permitted by statutory regulation or exceeds the permitted use, you will need to obtain permission directly from the copyright holder. To view a copy of this license, visit http://creativecommons.org/ licenses/by/4.0/.

(c) The Author(s) 2020 